\title{
Trajetórias de Joaquim Alberto Cardoso de Melo: Quincas, Um berro à vida
}

\author{
The life story of Joaquim Alberto Cardoso de Melo: \\ Quincas, Um berro à vida
}

Lenira Zancan ${ }^{1}$

Álvaro Hideyoshi Matida ${ }^{2}$

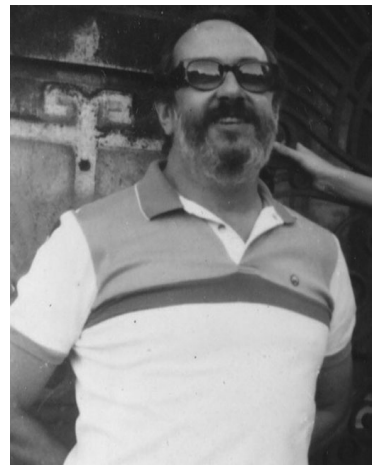

Abstract The article seeks to reflect on the contribution of Joaquim Alberto Cardoso de Melo (1936-1993) to the field of public health relating his life story and his scientific production with core issues of education and health, present in his time and which remain in debate to this day. His contribution resulted in the production of new meanings for health practices, with the understanding as social and transdisciplinary phenomena. Based on conversations with co-authors and friends and rereading of his texts, it was decided to approach his biography from: (i) his skills and participation in initiatives and practices of preventive medicine and popular education, which fomented the critical analysis of health education; (ii) his presence as an educator in public health courses throughout the country, eliciting the deconstruction of the theories and practices of education and health with managers, students, professionals and teachers; (iii) his availability for transdisciplinary dialogue with the humanities and social sciences in the search for "epistemological sutures" between reason and passion, capable of responding to the dilemmas and challenges of healthcare work. These three trajectories indicate that the performance of "Quincas" must be understood from his restlessness as a health professional and educator, engaged in the production of knowledge and practices related to the complexity of the phenomenon of life. Key words Education, Health work, Public health, Joaquim Alberto Cardoso de Melo
Resumo O artigo busca refletir sobre a contribuição de Joaquim Alberto Cardoso de Melo (19361993) ao campo da Saúde Coletiva relacionando sua trajetória de vida e sua produção científica com questões em seu tempo e que permanecem em debate na atualidade. Contribuição que resultou na produção de novos sentidos para as práticas em saúde, com a compreensão como fenômenos sociais e transdisciplinares. Das conversas com coautores e amigos, e releitura de seus textos, optouse por percorrer sua biografia através de: (i) sua formação e participação nas iniciativas e práticas da medicina preventiva e da educação popular, que nutriram a análise crítica da educação em saúde; (ii) sua presença como educador nos cursos de saúde pública em todo o país, exercitando com gestores, alunos, profissionais e professores a desconstrução das teorias e práticas da educação e da saúde; (iii) sua disposição ao diálogo transdisciplinar com as ciências humanas e sociais na busca de uma "sutura epistemológica" entre razão e pai$x a \tilde{o}$, capaz de responder aos dilemas e desafios do trabalho em saúde. Essas três trajetórias indicam que a atuação de "Quincas" deve ser entendida a partir de seu desassossego enquanto sanitarista $e$ educador, engajado na produção de conhecimento e práticas sensíveis à complexidade do fenômeno da vida.

Palavras-chave Educação, Trabalho em saúde, Saúde coletiva, Joaquim Alberto Cardoso de Melo

\footnotetext{
lenirafzancan@gmail.com

${ }^{2}$ Centro de Relações

Internacionais, Fiocruz.

${ }^{1}$ Departamento de Ciências Arouca, Fiocruz. Leopold Bulhões 1480, Manguinhos. 21041-210 Rio de Janeiro ciais, Escola Nacion de Saúde Pública Sérgio
} 


\section{Introdução}

Este artigo busca refletir sobre a contribuição de Joaquim Alberto Cardoso de Melo ao campo da Saúde Coletiva, relacionando sua trajetória de vida e sua produção acadêmica com as questões consagradas da educação e da saúde presentes em seu tempo, e que permanecem em debate na atualidade.

O desafio foi tecer um fio condutor que permitisse ao leitor reconhecer sua contribuição num contexto de mudanças paradigmáticas, com áreas de sombra e de luz, sem procurar uma visão linear e progressiva do conhecimento por ele produzido. Foi como percorrer um fita de moebius buscando delimitar, de acordo com os limites deste artigo, um começo e um fim nesta trajetória errante e circular que é a vida.

A pista que procuramos seguir para falar de sua contribuição nos foi dada pelo próprio Joaquim que, em um texto de 1992, publicado postumamente, escreveu:

Assim, pensar a educação, é pensar desde a minha biografia, onde estão incluídas muitas parcerias intelectuais e afetivas. Talvez por isso, pensar educação e saúde para mim, esteja marcado por vê-las como dimensões do ser humano em sociedade, onde me vejo como coadjuvante e coautor desse 'script' de várias e múltiplas vozes; de re-produção da vida, de real-iz-ação do real e da de-construção da existência ${ }^{1}$

Procuramos então, através de sua trajetória de vida, retomar as "problemáticas obrigatórias" do campo da saúde que ele refletiu, em especial na área da educação em saúde. Foi esta área de "saber-poder" que ele buscou investigar, compreendendo seu discurso e suas práticas como expressão do tensionamento entre projetos distintos de sociedade, mostrando sua articulação com outros discursos oriundos de áreas do pensamento social de sua época. São estas problemáticas obrigatórias, que procuramos refletir, temas que tornam as discussões e os autores contemporâneos entre si, pois mesmo quando discordam, concordam sobre o que devem discutir e divergir ${ }^{2}$.

Nossa tentativa é então revisitar sua produção bibliográfica e reavivar a memória afetiva de suas parcerias, daqueles que com ele conviveram e coproduziram, e que o chamavam de Quincas. Memórias que encontramos publicadas em artigos, homenagens e que ressoam ainda pelos corredores da Escola Nacional de Saúde Pública (ENSP) quando seu nome é evocado, fazendonos rever aquilo que nos é comum, aquilo que circunda e une os amigos, colegas e eternos alu- nos $^{3,4}$. É no diálogo com estas memórias que fomos tecendo este artigo.

Sua leitura transdisciplinar e erudita, transitando da literatura à filosofia, da matemática à psicanálise e à antropologia, com que refletiu o campo da educação e da saúde, marcou toda uma geração de sanitaristas. A busca de realizar uma sutura epistemológica entre razão e paixão, entre o dentro e o fora, entre corpo e mente, na conjunção do "e" no lugar do "ou", está presente no livro "Educação, Razão e Paixão", que ele organizou. No artigo de mesmo nome, em coautoria com Fermim Roland Schramm, podemos encontrar uma tradução do que foi sua prática de educador. Referindo-se a Sócrates, pontua:

Cria um método de conhecimento - o diálogo - que consta de dois momentos: o primeiro é o do questionamento (ironia), o segundo é o da maiêutica (partejar o conhecimento, trazendo-o à luz). Ao contrário dos sofistas, para quem ensinar é influenciar, para Sócrates - que recusava admitir que ensinava - o conhecimento é extraído de dentro, não dado de fora, pois já estava lá, embora disso não se soubesse ${ }^{5}$.

Desde sua formação e encontros com os movimentos sociais, do ensino nos cursos de saúde pública, nas pesquisas e nos projetos comunitários, como também nas experiências de gestão em secretarias de educação e de saúde em todo o país, Joaquim nos convidou a exercitar uma 'razão razoável' que possa dar conta, apesar de todas as suas limitações, do agir humano, das suas tensões entre desejo de dominação e necessidade de comunicação, entre atividades predatórias de conquista e reflexões conciliatórias de preservação $0^{5}$.

Como um reconhecimento de sua sábia presença entre nós, buscamos indicar questões atuais no campo da promoção da saúde que já se encontravam refletidas em suas análises, em sua obra inacabada.

\section{As práticas de saúde e a educação: visão crítica e emancipatória}

Nascido em 26 de outubro de 1936, na cidade de Pirajuí, São Paulo, formou-se em odontologia na USP em 1961, onde especializou-se em Odontologia em Saúde Pública em 1966 e em Educação em Saúde Pública em 1967. Foi neste período seu primeiro contato com a Fundação Serviço Especial de Saúde Pública (FSESP), em Pernambuco, para avaliar possibilidades de estágio para alunos da pós-graduação da USP, e em Minas Gerais, como estagiário do curso de Educação em Saúde Pública. 
eriências vivenciadas por toda uma geração, engajados nos ideais de uma revolução cultural, da valorização da cultura popular e da educação como expressão desta cultura, instrumento de emancipação das classes populares.

Joaquim sempre falava destas experiências como fundamentais para sua formação de sanitarista. De seu percurso da odontologia para a saúde pública, ele dizia, foi como se deslocar, entre o céu da boca e o chão da língua, para o espaço sidereal. Nesse deslocamento, foi marcante seu encontro com o educador Paulo Freire, com quem conviveu no período em que esteve na USP e com quem trabalhou, posteriormente, na Secretaria de Educação da cidade de São Paulo.

No Departamento de Medicina Preventiva e Social da UNICAMP atuou, entre 1971 e 1977, como docente em disciplinas de ciências sociais aplicadas à saúde, educação em saúde, saúde escolar, medicina comunitária e educação popular. Participou de inúmeros processos de formação de docentes e na supervisão de residentes em projetos de extensão, em particular no Centro de Saúde de Paulínia, São Paulo, através do Laboratório de Educação para Medicina de Comunidade (LEMC). Colaborou assim com as primeiras experiências de organização da atenção primária em saúde, junto com Célia Leitão Ramos, Célia Almeida, entre outros. Em Paulínia, atuou ainda como membro do Conselho de Saúde de Comunidade e da Comissão Municipal do Mobral e na Coordenadoria de Promoção da Saúde da Comunidade, entre 1973 e 1975.

Este convívio com os profissionais, no cotidiano das práticas em saúde, certamente refletiu-se em sua tese de doutoramento, defendida em 1976. Com o título A prática da Saúde e a Educação ${ }^{6}$, Joaquim revisou mais de 50 anos de produção sobre o tema da educação sanitária ou educação em saúde no Brasil e contribuiu para o movimento de crítica à medicina preventiva, dentro do modelo privatista e elitista do sistema de saúde vigente. Sua tese revelou a influência do modelo sanitarista norte-americano na configuração das práticas institucionais nos serviços de saúde pública e na formação dos educadores em saúde brasileiros, como agências e agentes de modernização de há- bitos e comportamentos ou como catalisadores do desenvolvimento comunitário.

Quincas contribuiu assim para a compreensão da educação e da saúde como fenômenos históricos e sociais, a partir da introdução da sociologia crítica no campo, em sintonia com as análises, dentre outros, de Luiz Pereira e Cecília Donnangelo?

Esta trajetória de vida e trabalho, nas décadas de 60 e 70, está expressa também no artigo publicado nos Cadernos do CEDES, sob o título Educação sanitária: uma visão crítica ${ }^{8}$. Partindo de sua tese de doutoramento, o estudo identificou três principais discursos que conformaram a educação sanitária e a educação em saúde no Brasil. Retomaremos aqui esta análise, na medida em que a consideramos ainda hoje necessária à abordagem da educação e promoção da saúde.

O primeiro discurso da educação na área da saúde caracterizou-se pelo entusiasmo e otimismo pedagógico das ações preventivas da década de 20, com a criação dos centros de saúde e a ênfase na escolarização. Esses mecanismos seriam capazes de incorporar grandes camadas da população na senda do progresso nacional e na formação do novo homem brasileiro. É esse o discurso que orienta a ação das visitadoras sanitárias nas décadas de 30 e 40. Após o período de retomada da polícia sanitária, com baixo investimento nas ações educativas e forte presença da repressão e exclusão das camadas populares que viviam fora do mercado formal de trabalho, o discurso pedagógico da educação sanitária volta-se para o apoio à organização comunitária, para a participação e integração dos setores 'atrasados' no desenvolvimento nacional. A Fundação Serviço Especial de Saúde Pública (FSESP), exerce um papel importante neste período. Fruto de acordo com os EUA, para extração da borracha e produção de alimentos, essa cooperação traz consigo a ideologia do Desenvolvimento de Comunidades, apoiada na teoria da marginalidade e na visão liberal do desenvolvimento das capacidades humanas. A educação de adultos torna-se um importante instrumento de inclusão das classes populares, visando à formação da força de trabalho no meio rural para responder as necessidades de modernização da agricultura e no preparo de mão de obra para as indústrias pesadas (automobilísticas) que vão se implantando (nacionais e estrangeiras). Nesta perspectiva, ao profissional da saúde caberia [...] diagnosticar, identificar as 'barreiras' sociais, econômicas e culturais oferecidas pela população e propor medidas 'educativas' que possam 'quebrar' essas barreiras. 
É neste período que o discurso da educação popular começa a se expandir com as experiências bem sucedidas de alfabetização de adultos, utilizando o método de problematização e reflexão da realidade, desenvolvido por Paulo Freire? O método foi aplicado em áreas rurais, alfabetizando um número expressivo de trabalhadores em poucos dias. Entusiasmado com o resultado, o então presidente João Goulart adotou a ideia e apoiou a realização de cursos de formação de coordenadores em diversos estados brasileiros, visando alfabetizar dois milhões de alunos. Com o golpe militar em março de 1964, o discurso e a prática da educação popular é considerado subversivo e ameaçador à ordem constituída e as políticas de saúde pública engendram um terceiro discurso. Organiza-se então, a partir de 1967, a chamada educação em saúde ou educação para a saúde. Este discurso funda-se na estratégia de participação dos indivíduos e das comunidades para que assumam as responsabilidades com a melhoria de sua saúde 2 .

A educação em saúde é assim vista como um instrumento para que as classes populares assumam seu papel no desenvolvimento econômico e social e aprendam, através do saber da saúde, a viver de forma mais saudável. É um discurso que também dá sustentação à escola pública voltada para a formação técnica. Essa foi a contribuição da saúde pública no caminho para a inclusão no mundo do trabalho, no modelo de cidadania regulada, que caracterizou as políticas de proteção social no Brasil.

É neste contexto que Joaquim inicia sua formação e vivencia as primeiras experiências no campo da educação e da saúde. Foi sobre este lugar da educação e da participação comunitária, num contexto de crescente autoritarismo político e do projeto liberal de sociedade, que Quincas produziu sua crítica ao discurso e à prática da educação em saúde.

A subordinação da educação em saúde à saúde pública é decorrente de uma específica visão de homem e de mundo, da saúde e da educação. As ações de saúde, traduzidas como prestação de serviços preventivos de um lado e curativos de outro, reduzem o conceito de saúde-doença, dicotomizando a população em sadios e doentes [...] A Saúde Pública se distancia cada vez mais da realidade concreta das relações homem-meio ${ }^{6}$.

Essa crítica ao modelo disciplinador e modernizador para a formação do homem sadio e trabalhador, útil ao sistema, marcou o discurso político da saúde e da educação. Crítica à uma concepção naturalizada de educação e de saúde como instrumentos do desenvolvimento humano e social, desconsiderando a dialética das relações entre educação, saúde e sociedade.

Repensar este sistema pedagógico e as práticas de educação e de saúde dele decorrentes, atrelando este repensar às necessidades, possibilidades e movimentos próprios das classes populares na construção de um novo modelo de políticas públicas, foi (e ainda é) uma "questão obrigatória” para a Saúde Coletiva.

Em que pese as mudanças no contexto sociopolítico e os avanços científicos e tecnológicos no campo da saúde, nos dias atuais ainda prevalece um discurso da educação em saúde como instrumento para inclusão social e aquisição de hábitos saudáveis. Mesmo após tantos anos de análise histórico-estrutural, em que as iniquidades e condições socioeconômicas foram incorporadas enquanto determinantes e condicionantes da qualidade de vida ${ }^{10}$.

Não são outras as contradições do discurso da Promoção da Saúde, enquanto política pública orientada a responder as mudanças no perfil epidemiológico da população através da racionalidade biomédica, que correlaciona doenças a comportamentos ou ambientes de risco. Política orientada a promover saúde através de mudanças nos estilos de vida, na culpabilização e na medicalização, com pouca ou nenhuma adequação aos contextos, às desigualdades de oportunidades, à diversidade de modos de vida, às dinâmicas sociais, simbólicas e afetivas historicamente construídas $^{11,12}$.

\section{O trabalho em saúde: quem educa quem?}

Joaquim veio para o Rio de Janeiro em 1977, juntamente com o chamado "grupo de Campinas", tornando-se professor titular do Departamento de Ciências Sociais da Escola Nacional de Saúde Pública (ENSP), da Fiocruz. Até 1993, quando morreu no auge da sua maturidade intelectual, contribuiu na criação e desenvolvimento de grande parte dos cursos, programas de educação em saúde e projetos comunitários que se tornaram referências para a saúde pública e a educação em saúde no Brasil.

Coordenou, em 1978 e 1979, o curso Treinamento Avançado em Serviço, que deu origem à Residência Multiprofissional em Saúde Pública e Medicina Social que formou grande parte do quadro de pesquisadores e professores da ENSP. Atuou na coordenação, docência e orientação de alunos do Curso de Especialização em Saúde Pública na ENSP e dos Cursos Descentralizados, 
realizados em parceria com as Universidades e Escolas de Saúde Pública em todas as regiões do país. Até seu encontro, em 1991, com os alunos da Escola Politécnica de Saúde "Joaquim Venâncio"/Fiocruz, nas aulas de filosofia, Joaquim exercitou sua compreensão da educação como mediação das relações entre professor/aluno e profissionais/pacientes.

Nos espaços formais e informais da educação e da saúde, no diálogo com as diversas categorias profissionais, campos do conhecimento, experiências de trabalho e instituições de formulação e implementação de programas e políticas - que estão descritos em seu currículo e que marcaram a memória de seus parceiros, Joaquim foi um interlocutor de escuta atenta e olhar acolhedor.

Um exemplo de sua presença na diversidade de processos de inovação no campo da educação em saúde pública foi sua participação na implantação do Programa de Preparação Estratégica de Pessoal da Saúde (PPREPS) articulado ao PIASS (Programa de Interiorização da Saúde e Saneamento). Estes programas visavam ampliar o sistema público de saúde e tinham uma forte ênfase na formação de técnicos. Na Bahia, Joaquim colaborou, junto com Sérgio Arouca, Hortência Urpia de Holanda, Maria Nilde e Elza Lobo, com Tânia Celeste Nunes e Luiz Augusto Galvão, para a compreensão dos fundamentos da formação de nível médio e de suas práticas no contexto de reorientação do sistema de saúde. Esse trabalho antecedeu o Projeto Larga Escala e resultou na reformulação dos cursos de auxiliares de saúde. Nesse processo, incorporou-se o pensamento crítico e tratou-se a formação do auxiliar como a formação de um sujeito, a partir do modelo de educação popular de Paulo Freire.

Foi deste período também sua colaboração na construção da Escola Politécnica de Saúde Joaquim Venâncio/Fiocruz, junto com Luiz Fernando Ferreira, Julio França Lima, Bianca Antunes Cortes e André Malhão. Nesse processo, merece destaque a Semana de Estudos, coordenada por ele, com participação da equipe de profissionais da Escola para o aprofundamento e o enriquecimento do conceito de politecnia, a partir de Antônio Gramsci, focado na abordagem do trabalhador em saúde enquanto um agente de mediação para emancipação das classes populares. Também foi resultante desse processo a organização do Seminário Choque Teórico que serviu de base conceitual e operacional para a formação de técnicos em saúde e para a seleção dos professores que viriam compor a primeira equipe do Curso Técnico de Segundo Grau. Neste curso, Joa- quim, a partir de 1991, passou a lecionar filosofia aos adolescente, o que fez com grande prazer e competência até sua morte em 1993.

Importante destacar, também, seu protagonismo na realização dos Seminários de Educação para a Saúde junto ao Departamento de Saúde do Serviço Social do Comércio (SESC) do Rio de Janeiro, de 1978 até 1987, e, posteriormente, na colaboração com o Departamento Nacional do SESC, implementando os serviços de prevenção daquela instituição. Organizados numa perspectiva transdisciplinar, constituíram-se em um espaço privilegiado para a crítica do modelo tradicional da educação em saúde, repensando as instituições e os agentes - as relações entre profissionais e pacientes a partir das contradições inerentes às relações sociais entre classes, interesses e saberes em disputa.

Neste contexto de crise dos modelos tradicionais da educação e da saúde como instrumentos de "adaptação à ordem social", na formação das “ boas consciências" ou dos "corpos sadios”, Joaquim também foi central na desconstrução do saber técnico científico como ferramenta capaz de responder à complexidade do processo de produção social da saúde, em especial no interior dos serviços de saúde.

Este debate está refletido no artigo que ele escreveu com Célia Leitão Ramos e Jussara Soares, onde encontramos uma síntese da crise do modelo médico-centrado e a emergência de novos paradigmas para a compreensão do trabalho em saúde:

Nesta perspectiva de objetividade, o que passa a existir é a relação entre a instituição médica, através de seus funcionários, e a doença do paciente. $O$ Médico não precisa mais ouvir o paciente; pelo contrário, suas informações somente podem confundir, dada a subjetividade a elas inerente. A organização e o empresariamento dos serviços, a divisão técnica do trabalho, o assalariamento dos profissionais liberais e o desenvolvimento de uma tecnologia altamente sofisticada, vêm transformando a relação entre os profissionais e os pacientes, que estão submetidas às técnicas, ao discurso e à ordem médica. Nesse processo de exclusão dos sujeitos resta uma relação retificada, objetivada, autoritária e inculcadora de um saber que pretende estabelecer e impor a ordem médica. Esta ordem, este saber que se impõe pelo poder do discurso médico, carrega consigo o saber e o poder de uma ordem social dominante, a ordem capitalista ${ }^{13}$.

A educação que se realiza no cotidiano do trabalho em saúde deve ser compreendida, assim, a partir da dialética nas relações de produção e 
reprodução da ordem social e da luta pela hegemonia, mantendo a coerência da visão crítica do campo da saúde. Tomando o trabalho de Cury ${ }^{14}$ como referência, Joaquim reafirma que a dialética reprodução-contradição-totalidade permite perceber como as instituições não só refletem as estruturas, mas também cooperam para produzir e reproduzir as relações sociais. Ou seja, a educação em saúde não é mero instrumento de reprodução das condições de dominação de uma classe (ou saber) sobre outro, pois as relações sociais se dão num movimento que não somente confirma antagonismos, mas também aponta para a possibilidade de sua superação. A contradição traz em si a possibilidade de que se construa uma outra direção, uma outra hegemonia, tanto para a superação das condições de subordinação das classes trabalhadoras como para a construção de um saber menos regulador e disciplinador dos sujeitos. Um saber que reconheça que a população apesar de esmagada pelas condições de vida que enfrenta, emite suas propostas e representações, constituindo-se também como intelectuais portadores de saberes $[\ldots]^{13}$.

Estas reflexões foram produzidas também no diálogo com Victor Valla, teórico e militante do campo da educação popular em saúde, cuja parceria tem registro no artigo "Sem educação, ou sem Dinheiro" de $1987^{15}$.

Esta possibilidade de tomar outra direção, de construir um outro saber, Joaquim buscou também junto aos movimentos populares nas favelas no Rio, em especial da Região da Leopoldina. Em Manguinhos e na Maré, ele transitou nos mais diversos espaços de luta política e práticas emancipatórias, desde conquistas nas associações de moradores até as atividades lúdicas que desenvolvia com crianças e adolescentes na sala de espera do Centro de Saúde Escola da ENSP. Em todos estes espaços de produção da saúde, Joaquim contribuiu com seu método de reflexão e problematização para a ampliação do conceito de saúde como "compreensão de vida", como no título da publicação que resultou de convênio entre o MS e o MEC para a produção de materiais didáticos para professores e alunos de $1^{\circ}$ e $2^{\circ}$ graus, do qual ele participou.

O educar para a saúde não é ensinar, não é buscar algo que está fora dos sujeitos, um conhecimento ou atitude que se transmite de um que sabe para outro que não sabe. A educação em saúde se dá no processo de reflexão dos sujeitos a cerca do mundo e de si mesmos, da subjetivação da saúde e da doença.

Assim, Joaquim incorporou em sua prática de educador a problematização, não apenas como método de ensino-aprendizagem, mas principalmente como modo de exercitar a consciência crítica da realidade, um modo de estar no mundo, onde é necessário questionar os valores e fazer escolhas. Refletir para desvelar os mecanismos de dominação e de resistência que constituem as estruturas dos processos sociais e políticos, desde aqueles do âmbito das práticas em saúde, até os da relação homem-natureza, da questão ecológica, que tornou-se também uma questão “obrigatória” do campo da saúde.

Faz todo o sentido, também, seu diálogo com a psicanálise, expresso nas parcerias desenvolvidas com Sherrine Njaine Borges e Jurema Pureza Valente, buscando compreender a ruptura histórica corpo/mente, sujeito/objeto presente na saúde pública ${ }^{16,17}$.

\section{Algumas palavras (memórias), enfim}

Joaquim contribuiu sobremaneira com a distinção e aprofundamento da educação dentro do campo da saúde. Ao mesmo tempo em que procedeu a uma crítica radical da educação sanitária como mecanismo de normatização e controle sobre a sociedade, enfatiza a educação como "prática da liberdade" . Procura desconstruir a visão eminentemente racionalista e funcionalista da educação e do trabalho em saúde. No seu lugar constrói uma perspectiva aberta, relacional da saúde e do humano, fundamentais para os processos educativos em saúde, para a formação dos profissionais e também na relação entre profissionais e pacientes nos serviços.

Essas de-construções, como Joaquim escreveu, tanto da educação em saúde como do trabalho em saúde, acontecem a partir da percepção de que a educação não ocorre, primordialmente, nos processos formais de ensino ou nas ações educativas nos serviços. A educação está presente em todo o fenômeno social, em toda a interação entre sujeitos, seja nas relações de dominação e exclusão do outro, seja nas relações que se constroem no diálogo, em uma horizontalidade dos discursos e dos sujeitos, na desconstrução do "discurso competente"18.

No lugar deste discurso que não reconhece o outro, Quincas nos convida a aprender junto com pacientes e alunos "impacientes", compreendendo seu discurso e sua experiência como coprodutores da saúde. Em seu desassossego ele dizia que não se transforma um serviço de saúde a partir de seus funcionários, mas antes através de seus usuários. A inclusão, a participação social nas diversas etapas da criação de uma ideia, até sua 
execução e avaliação sempre teve um lugar nos seus debates como educador e sanitarista.

Esta foi sua utopia e sua marca - o diálogo -, tanto em sala de aula como nos projetos comunitários que participou, escrevendo junto com muitos outros, em conjunto, a história da saúde coletiva em Paulínia, em Manguinhos, na Maré e em tantos outros lugares. Uma concepção da educação como "útero da liberdade com responsabilidade", no sentido da Paidéia dos gregos, que encontramos em outro momento de sua reflexão:

Algo da ordem do que vem à luz, que se nutre e se dirige para fora. Educar, no mundo grego, destinava-se a criar condições ao homem para que ele pudesse ser livre, autogovernar-se para poder governar e pensar os destinos da polis ${ }^{1}$.

Esta visão nos colocou, e nos coloca ainda, a todos, profissionais, professores, pesquisadores, engajados na produção de um conhecimento em saúde, de uma educação capaz de mediar as relações sociais em direção à equidade, integralidade e universalização do direito à saúde. Esta sua marca indelével, articulando o saber técnico científico ao conhecimento situado e significativo dos sujeitos para a real-iz-ação do mundo, o que encontramos hoje na chamada clínica ampliada ${ }^{19}$ e na promoção emancipatória da saúde ${ }^{10}$.

Por fim lembramos que Joaquim, com toda a sua sabedoria e consciência do "mal estar da humanidade", afirmava a empatia e a emoção como fundamentais para realizar uma crítica potente e transformadora do trabalho em saúde. Em suas palavras:

Assim, recuperar a paixão como sentimento é poder erotizar as relações, no sentido amoroso de unir-se, unir sem apagar as diferenças. Desta maneira, podemos pensar em desconstruir as relações sociais e as relações entre trabalhadores de saúde e a clientela, numa direção amorosa, da compaixão, consentimento, do compromisso. Poder resgatar aquilo que move, comove, emociona. Não seria este um caminho possivel para o reencantamento do universo, um reencontro com a vida, mesmo que seja para a morte?5

\section{Colaboradores}

L Zancan e AH Matida participaram igualmente de todas as etapas de elaboração do artigo. 


\section{Referências}

1. Melo JAC. Trabalho Educação e Saúde: da pedagogia à uma socio-antropologia das organizações de saúde - uma des-construção. In: Escola Politécnica de Saúde Joaquim Venâncio. Trabalho, educação e saúde: reflexões críticas de Joaquim Alberto Cardoso de Melo. Rio de Janeiro: EPSJV; 2007. p. 11-20.

2. Lima MA, Zancan L. O discurso da Educação em Saúde (1940 - 1980). In: Lima MA, Zancan L. Contribuição para análise de políticas públicas no Brasil: educação, saúde e mudança social. Rio de Janeiro: Cadernos do IFCH/UFF; 1991. p. 1-40.

3. Ferreira LF. Homenagem a Joaquim Alberto Cardoso de Melo. In: Amâncio Filho A, Moreira MCGB, organizadores. Saúde, trabalho e formação profissional. Rio de Janeiro: Fiocruz; 1997. p. 127-135.

4. Homenagens proferidas por Lenira Zancan por ocasião da inauguração do Centro de Estudos Joaquim Alberto Cardoso de Melo da EPSJV, em 1996, e da entrega do Premio Joaquim Alberto Cardoso de Melo da II Mostra de Ensino da FIOCRUZ, no ano de 2004 [arquivos pessoais].

5. Melo JAC, Schramm FR. Educação: razão e paixão. In: Cardoso de Melo JA, organizador. Educação: razão e paixão. Rio de Janeiro: ENSP; 1993. p. 19-26.

6. Melo JAC. A prática da Saúde e a Educação [tese]. Campinas: Unicamp; 1976.

7. Teixeira SMF. As ciências sociais em saúde no Brasil. In: Nunes ED, organizador. As ciências Sociais em Saúde na América Latina: tendências e perspectivas. Brasília: OPAS; 1985. p. 87-109.

8. Melo JAC. Educação Sanitária: uma visão crítica. $\mathrm{Ca}$ dernos do CEDES 1985; 4:28-43.

9. Freire P. Educação como prática da liberdade. Rio de Janeiro: Paz e Terra; 1967.

10. Buss PM. Promoção da saúde e qualidade de vida. Cien Saude Colet 2000; 5(1):163-177.

11. Castiel LD. Dédalo e Dédalos: identidade cultural, subjetividade e riscos à saúde, In: Czeresnia D, Freitas CM, organizadores. Promoção da saúde: conceitos, reflexões, tendências. $2^{\mathrm{a}}$ ed. Rio de Janeiro: Fiocruz; 2009. p. $207-$ 229.
12. Porto MFS, Pivetta F. Por uma promoção da saúde emancipatória em territórios urbanos vulneráveis. In: Czeresnia D, Freitas CM, organizadores. Promoção da saúde: conceitos, reflexões, tendências. $2^{\text {a }}$ ed. Rio de Janeiro: Fiocruz; 2009. p. 207-229.

13. Ramos CL, Melo JAC, Soares JCRS. Quem educa quem? Repensando a relação médico-paciente. In: Minayo C, Costa NR, Ramos CL, organizadores. Demandas Populares e Políticas Públicas. Rio de Janeiro: Vozes; 1989. p. 145-164.

14. Cury CR. Educação e Contradição. $2^{a}$ ed. São Paulo: Cortez Autores Associados; 1986.

15. Valla VV, Cardoso de Melo JA. Sem educação ou sem dinheiro. In: Minayo MCS, organizador. Saúde em estado de choque. Rio de Janeiro: Espaço e Tempo; 1987. p. 103-144.

16. Borges SMN. Vida na psicanálise. In: Melo JAC, organizador. Educação: razão e paixão. Rio de Janeiro: ENSP; 1993. p. 65-71.

17. Valente JP. Resgatando sentidos. In: Cardoso de Melo JA, organizador. Educação: razão e paixão. Rio de Janeiro: ENSP; 1993. p. 99-108.

18. Chaui M. Cultura e Democracia: o discurso competente e outras falas. São Paulo: Cortez Editora; 1987.

19. Campos GWS. Clínica e saúde coletiva compartilhadas: teoria Paidéia e reformulação ampliada do trabalho em saúde. In: Campos GWS, Bonfim JRA, Minayo MCS, Akerman M, Júnior MD, Carvalho YM, organizadores. Tratado de Saúde Coletiva. São Paulo: Hucitec; 2006. p. 53-92.

Artigo apresentado em 02/07/15 Aprovado em 05/08/15 